\title{
Importancia de las Enteroparasitosis como causa del Síndrome Diarreico Agudo del Lactante
}

\author{
Dra. Patricia Muñoz C., * Eric Saelzer, ${ }^{* *}$ Erich Schilling, ${ }^{* *}$ Antonio Atías, "Nancy Enríquez*** y Srta. Elisa Escobar"
}

\begin{abstract}
A group of 100 infants wilh severe diartheic syndrome (SDA) from the parasitologic point of view was studied by means of three methods of evacuation exams. A direct one dyed with a vital coloring (preen methyl) and observed in Foot chamber and two serial exans using the modified Telleman techniques and the PAFS one. In 35 cabes the exams were positives and in 20 pathogenic elements were isolated.

In 17 exam Entameoba histolytica parasites were present. In 4 exams Gicrdia lamblia and in I exam Hymeno* lepts nana.

In 2 of the 17 casea with amibiasia, psthogenic bacterials (Salmonella Typhymurium and Schigella flexnerie) were isolated in the feces and virus in 5 canes ( $\left(\mathrm{Poli}_{3}, \mathrm{ECHO}_{6}\right.$ and 4 non typific able virua). In some of the other cases virus was also isoloted.

The finding of amibiasis in an important number of infants was dicupaed. Its clinical form related to the nutritional condition and the adecuate envizonment dispositions for the infection was analyoed.

It becomes evident the necessity to consider the amibiasis in the differential dingnostic of the SDA.
\end{abstract}

La patologia prevalente en el lactante durante el período estival, en el síndrome diarreico agudo. Clásicamente, este síndrome ha sido atribuido a las enterobacteriáceas, criterio que ha inspirado las acciones terapéuticas reflejadas en el uso, muchas veces indiscriminado, de antibióticos. En los últimos años el desarrollo de técnicas específicas y de más fácil aplicación, ha permitido demostrar el importante rol que juegan loa virus en la patogenia de este cuadro.'

En relación a la importancia de los enteroparásitos en la etiologia de la diarrea aguda del lactante en nuestro pais, la literatura pertinente aporta escasas referencias. 2, 3,4 Esta situación pudiera explicarse por las dificultades técnicas que entraña este tipo de investigación y por el concepto generalizado entre los clínicos, de que los parásitos excepcionalmente constituyen la causa de este síndrome.

Sin embargo, los estudios coproparasitológicos de lactantes con diarrea aguda, solicitados a nuestro laboratorio, señalaban que el papel de los paraisitos no era tan excepcional. Por ello, decidimos estudiar

*Unidad de Parasitologia, Depto. Medicina y Preclinicos. Facultad de Medicina Occidente, Universidad de Chile.

**Depto. de Pediatria, Facultad de Medicina Occidente. Univereidad de Chile.

**"Laboratorio Central, Seceión Microbiologia. Hospital San Juen de Dios. prospectivamente la importancia de las parasitosie en la etiología de las diarreas agudas de verano. Además, nos interesó investigar algunos factores clíni$\cos$ y epidemiológicos que pudiesan tener relación con esta entidad clínica.

\section{MATERIAL Y METODO}

Se estudjaron 100 lactantes ingresados al servicio de Pediatría del Hospital San Juan de Dios, con diagnóstico de síndrome diarreico agudo, en el período de verano de 1978.

Desde el punto de vista parasitológico, ae efectuaron 3 exámenes de deposiciones: uno directo, en que las heces se observaron de inmediato en cámara de Foot, usando un colorante vital (verde de metilo al $1 \%$ ) y dos exámenes seriados mediante dos técnicas diferentes de concentración (método de Telleman modificado y método de PAFS). ${ }^{5}$

El diaguóstico de los trofozótos teñidos deEntamoeba histolytica, se hizo aplicando un criterio morfológico basado en el estudio de los caracteres del núcleo: existencia de endosoma central y puntiforme, cromatina dispuesta en finos gránulos adosados a la superficie interna de la membrana nuclear y/o la presencia de eritrocitos fagocitados en el citoplasma.

Además se efectuó un eatudio bacteriológico y 
virológico, cuyos resultados se publicarán próximamente.

\section{RESULTADOS}

De los 100 casos estudiados, en 35 los exámenes coproparasitoscópjcos resultaron positivos (Tabla l). En 20 se aislaron elementos patógenos y en otros 20 se encontraron comensales. En 5 hubo asocjación de patógenos y comensales (Tabla 2). Los comensales encontrados fueron Entamoeba coll y Endolimax nana.

TA B L A 1

Resultado de exámenes coproparasitológicos en 100 lactantes con Síndrome Diarreico Agudo

\begin{tabular}{lc}
\hline Resultado & N. \\
\hline Exámenes positivoes & 35 \\
Exámenes negativos & 65 \\
\hline Total & 100 \\
\hline
\end{tabular}

TABLA 2

Elementos patógenos y comensales en 35 exámenes coprológicos positivos

\begin{tabular}{lr}
\hline Sólo elementos parásios & 15 \\
Sólo elementos comensales & 15 \\
Parásitos y comensales & 5 \\
\hline Tótal & 35
\end{tabular}

De los 20 pacientes en que se encontraron elementos parasitarios patógenos, se pesquisó en 17 casos
Entamoeba histolytica (en 15 como elemento parasitario único); dos casos con quistes de Giardia lamblia y un caso con huevos de Hymenolepis nana (Tabla 3).

\section{TABLA 3}

Etiología parasitaria en 20 lactantes con Síndrome Diarreico Agudo

\begin{tabular}{lc}
\hline Parásitos & N. ${ }^{\circ}$ casos \\
\hline Entamoeba histolytica & 15 \\
E. histolytica + Giardia lamblia & 2 \\
Giardia lamblio & 2 \\
Hymenolepis nana & 1 \\
\hline Total & 20 \\
\hline
\end{tabular}

En 9 de los 17 casos en que se aisló Entamoeba histolytica, el diapnóstico se hizo por el hallazgo exclusivo de trofozoitos de $E$. histolytica al examen directo con tínción vital y observado en cámara de Foot. En 7 de estos 9 casos las otras técnicas de exámenes parasitológicos dieron resultados negativos. En los 8 casos restantes se encontraron trofozoítos en uno o en ambos métodos de concentración. En ningún caso hubo hallazgo de formas quíaticas.

A relacionar el gupo de lactantes en los cuales se aisló algún elemento parasitario patógeno con la edad y antecedentes de lactancia materna, encontramos que 16 eran menores de 12 meses de edad y que la mayoría $(80 \%)$ no había recibido leche materna.

Los casos más precoces de infección parasitaria fueron 3 lactantes menores de 3 meses de edad.

La incidencia de otras etiologías infecciosas (viral y bacteriana) se resumen en la Tabla 4.

TABLA 4

Etiología parasitaria y de otros agentes patógenos en 20 lactantes con Sindrome Diarreico Agudo

\begin{tabular}{|c|c|c|c|}
\hline Parásitos & N. ${ }^{\circ}$ Casos & Virus & Bacterias \\
\hline & 9 & 一 & - \\
\hline \multirow[t]{5}{*}{ Entamoeba histolytica } & 1 & - & Saimonella typhimurium \\
\hline & 1 & Coxackie $B_{3}$ & Shizella flexnerie \\
\hline & 1 & Polio 3 & - \\
\hline & 1 & Virus no tificable & - \\
\hline & 1 & Echo $_{6}$ & - \\
\hline \multirow{2}{*}{ E. histolytica + G. lamblia } & 1 & $\rightarrow$ & - \\
\hline & 1 & Polio & - \\
\hline \multirow[t]{2}{*}{ Giardia lamblia } & 1 & - & - \\
\hline & $\mathbf{l}$ & Coxackie $\mathrm{B}_{3}$ & - \\
\hline Hymenolepis nana & 1 & Coxackie $\mathrm{B}_{3}$ & - \\
\hline
\end{tabular}


De los 17 casos en que se ajọló Entamoeba histolytica, en uno se identificó Salmonella typhimurium y en otro, Shigella flexnerie en las deposiciones.

La asociación de parásitos con virus fue más frecuente. En 4 casos de infección por Entamoeba histolytica hubo asociación en virus: en 2 , con virus Polio ${ }_{3}$, uno con un virus no tipificable y otro caso con el virus $\mathrm{ECHO}_{6}$.

En los dos niños en que se encontró G. lamblia como único parásito, ge asoció en un caso, a un virus Coxackie $B_{3}$. El único caso con $H$. nana se asoció a un virus Coxackie $B_{3}$.

Al relacionar el estado nutritivo con la etiologia parasitaria en estos lactantes, se observó que más del $80 \%$ de ellos eran portadores de una desnutrición grado II o III y que provenían de un ambiente socioeconómico regular o malo en el $90 \%$ de los casos.

Otro parámetro investigado fue el grado de deshidratación. En general se observó que ésta fue de grado I (leve), cuando sólo se aislaron parásitos y de grado II o III (moderada o grave), cuando existió asociación a otro agente patógeno: virus y/o bacterias.

No se encontró relación estadísticamente significativa entre la etiologia parasitaria y el tipo de deshidratación, la intensidad de la diarrea, y los djas previos de evolución. Tampoco hubo relación entre presencia de sangre y mucus en las deposiciones y hallazgo de E. histolytica.

\section{COMENTARIO}

La observación de una incidencia de $20 \%$ de parásitos patógenos en las diarreas agudas del lactante aparece como un hecho liamativo por su magnitud.

La aplicación de técnicas adecuadas de examen coproparasitológico ha mejorado el diagnóstico especialmente el de la $E$. histolytica, parásito capaz de causar cuadros diarreicos de extrema gravedad. ${ }^{6}$

Ha sido demostrado ${ }^{2}$ y lo corrobora el presente trabajo, que los exámenes parasitológicos seriados de deposiciones, examinados con técnicas corrientes no son los jdeales para el diagnóstico del trofozoito hematófago, propio de la amibiasis invasora. Fue el estudio directo en cámara de Foot, instalada cerca del lugar de recolección de la muestra de deposición y su inmediato procesamiento el que permitió aislar trofozoitos de $E$. histolytica y confirmar así el diagnóstico de amibiasis invasora en 9 de los 17 casos. En 7 de estos 9 casos otras técnicas no fueron capaces de identificar la presencia de parásitos, lo que subraya las limitaciones ya mencionadas.

Sin embargo, creemos que estamos asistiendo a un incremento real de las enteroparasitosis, al igual que otras infecciones por transmisión fecal-oral, tales como la hepatitis y la fiebre tifoidea. Este incremento se debería a los defectos del saneamiento am- biental y a las precarias condiciones socioeconómicas de los pacientes que consultan en el hospital.

En 15 de los 18 casos en que se aisló un enteroparásito asociado a un síndrome diarreico agudo, la edad del paciente era inferior a los 9 meses. Estimamos que este hecho se relaciona con el destete precoz y con la defectuosa manipulación de la aljmentación de los niños.

En 13 casos se pudo suponer una etiología parasitaria pura y en 12 de éstos, amibiana, ya que no se aislaron otros agentes patógenos.

A diferencia del nin̄o mayor y del adulto, en los cuales el síndrome disentérico es la manifestación mâs frecuente de la amibjasis aguda intestinal, en el lactante lo es la enterocolitis.

En relación a la asociación con otros agentes etiológicos observamos que en 3 casos se asoció a virus Polio $_{3}$, en niños que tenían entre 6 y 9 meses de edad, época que coincide con los esquemas de inmunización enti-Polio. ${ }^{?}$

La asociación de parásitos y bacterias patógenas hacen difícil valorar cuál de los agentes juega el rol primordial en la etiologia de la diarrea aguda.

De esta experiencia se desprende la necesidad de considerar la etiología amibiana en el diagnóstico diferencial de la diarrea aguda del lactante en nuestro medio.

\section{RESUMEN}

Un grupo de 100 lactantes con Síndrome Diarreico Agudo (SDA) fue estudiado desde el punto de vieta parasitológico, mediante tres métodos de exámenes de deposiciones: uno directo, teñido con un colorante vital (vende de metilo) y observado en cámara de Foot y.dos exámenes seriados utilizando las téenicas de Telleman modificada y la de PAFS. En 35 casos los exámenes fueron positivos y en 20 se aislaron elementos patógenos. Los parásitos encontrados fueron Entamoeba histolytica en 17, Giardia lamblia en 4 e Hymenolepis nana en 1.

De los 17 casos con amibiasis, se aislaron en las heces bacterias patógenas en 2 (Salmonella Tiphymurium y Schigella flexnerie) y virus en 4 (Polio, $\mathrm{ECHO}_{6}$ y un virus no tipificable). En algunos de los demás casos también se ajslaron virus.

Se discute el hallazgo de amibiasis en un importante número de lactantes y se analiza su forma clínica y su relación con el estado nutritivo y las condiciones ambientales propicias para la infección.

Se concluye en la necesidad de considerar a la amibiasis en el diagnóstico diferencial de los SDA del lactante.

\section{REFERENCIAS}

\footnotetext{
1Wu, E.; Grada, C.; Avendaño, F, y Corey, G. "Etiologia viral de la diarrea infantil". Rev. Chil. Ped. . 46: 119, 1975.
} 
${ }^{2}$ Athos, A.; Atwiz-Esqide, F.; Escobar, E,; Schilling, E. "Amibiesis inteatinal invasora del lectente". Rev. Med. Cbile, i05: 456. 1977.

${ }^{3}$ Prado, V,; Linch, B.; Noemf, I.; feyes, H. "Etjologáa micrubiana de la diarrea aguda con deshidralación en lectantes chilenos. Verano 1976-77. Hospital Luis Calvo Mackenna. Area de Salud Oriente de Suntiago". Bol. Vig. Enf. Trans. Zoon., 4(5): 2, 1977. ${ }^{4}$ Prado, V.; Lurch, B.; Noemí, I.; Reyes, H. "Etiología microbiana de la diarrea en lactantea chilenos. Consultorios periféricos. Area de Salud Oriente de Santiago". Bol, Vig. Enf. Trans. Zour. 4(10): 3. 1977. 5t Atas, A. y Neghme, A. Parasitologia Clinjeo. Edit. Intermédita, Bs. AireB.1979.

'Atías, A.; Ossa, P.; Soto, J.R.; Vela, H.; Nutrez, R. y Hojas, $H$ "Amibiasis intestinal invasoca: deacripción de 5 casos fatales". Rev. Med. Chile, 103: 201, 1975.

'Wu, E.; Contreras, G.; Ohlboum, A.; Gallo, A.; Conzalez, C. y Gilabert, B. "Esludio sobre la etiologia viral de les diarsean agrdas del lactente e influencia de la racunación Sabin oobre la flora de coterovirus". Rer. Chilena Ped., 42: 225, 1971. 